\title{
Sistemas osso-implante ex vivo utilizando haste intramedular polimérica para imobilização de fraturas femorais em bovinos jovens
}

\author{
Ex vivo bone-implant systems using polymeric intramedullary nails for fixation of femoral \\ fractures in young calves
}

\begin{abstract}
Odael Spadeto Junior ${ }^{\mathrm{I}, \mathrm{II}}$ Luciano Brito Rodrigues ${ }^{\mathrm{II}, \mathrm{IV}}$ Wellington Tadeu Vilela Carvalho ${ }^{\mathrm{I}, \mathrm{V}}$ Deliene de Oliveira Moreira ${ }^{\mathrm{I}}$ Cyril Alexandre De Marval ${ }^{\mathrm{VI}}$ Cláudio Gomes da Costa $^{\mathrm{VII}}$ Geraldo Eleno Silveira Alves ${ }^{\mathrm{I}}$ Estevam Barbosa de Las Casas ${ }^{\mathrm{III}}$ Rafael Resende Faleiros ${ }^{\mathrm{I} *}$
\end{abstract}

\section{RESUMO}

O desenvolvimento de novos aparatos usando materiais disponíveis e de baixo custo pode ser uma alternativa viável para o tratamento cirúrgico de fraturas em ossos longos de bovinos. $O$ objetivo deste estudo foi avaliar a resistência mecânica de fêmures de bovinos jovens com fratura diafiseal, imobilizados com hastes intramedulares bloqueadas, compostas por diferentes polímeros. Para tanto, testes físicos de compressão e flexão, por meio de uma máquina universal de ensaios foram realizados em quatro grupos distintos de seis fêmures obtidos de bovinos jovens. Em um dos grupos, os ossos foram mantidos íntegros (grupo controle), enquanto que os outros os ossos, foram fraturados e imobilizados com uma haste intramedular bloqueada, composta por polipropileno, poliacetal ou poliamida (uma para cada grupo). Independente do polímero utilizado, nenhuma das hastes estudadas ofereceu aos fêmures fraturados resistência comparável ao osso íntegro, quando consideradas em conjunto as forças de flexão $e$ compressão. A concordância desses achados com resultados in vivo previamente publicados, demonstra que a metodologia utilizada para testes ex vivo pode ser útil na seleção de materiais mais resistentes para confecção de novos modelos.

Palavras-chave: fêmur, haste bloqueada, testes físicos, biomateriais, bovino.

ABSTRACT

The development of new devices using available and low cost materials may be an useful alternative for the treatment of long bone fractures in large animals. The aim of this study was to evaluate the mechanical strength of young bovine femur with diaphyseal fracture fixed with different polymeric intramedullary nails. Bending and compression tests using a universal machine were carried out in 4 distinct groups of 6 femurs from young calves. In one of the groups bones were intact while in the other three fractured bones were fixed using an intramedullary nail made of polypropylene, polyacetal or polyamide (one for each group). Considering bending and compression tests together, none of the used polymers offered strength to the fractured bones similar to the intact ones. The agreement of this findings with those from previous published in vivo results indicates that the employed ex vivo methods for mechanical assays may be useful in the search of stronger materials to be used in development of new devices.

Key words: femur, interlocking nail, mechanical tests, biomaterial, bovine.

\section{INTRODUÇÃO}

A recuperação de fraturas ósseas é um problema médico frequente, sendo as fraturas em ossos longos uma das ocorrências mais comuns, e que tem demandado muitos estudos referentes às suas formas de tratamento. $\mathrm{O}$ avanço tecnológico tem permitido o desenvolvimento de grande variedade de instrumentos,

'Departamento de Clínica e Cirurgia Veterinárias, Pós-graduação em Ciência Animal, Universidade Federal de Minas Gerais (UFMG), Av. Antonio Carlos, 6627, 30123-970, Belo Horizonte, MG, Brasil. E-mail: faleiros@ufmg.br. *Autor para correspondência. "Hospital Veterinário, Centro Universitário de Vila Velha (UVV), Vila Velha, ES, Brasil.

IIIPrograma de Pós-graduação em Engenharia Mecânica, Escola de Engenharia, UFMG, Belo Horizonte, MG, Brasil

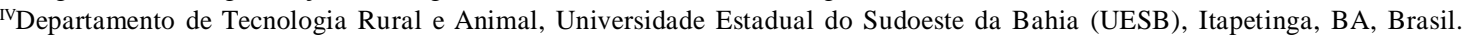

${ }^{\mathrm{V}}$ Instituto Federal do Sudoeste de Minas Gerais, Barbacena, MG, Brasil.

${ }^{\mathrm{v}}$ Departamento de Medicina Veterinária, Pontifícia Universidade Católica (PUCMinas), Betim, MG, Brasil.

${ }^{\mathrm{VII} L a b o r a t o ́ r i o ~ R o b e r t ~ H o o k e, ~ F u n d a c ̧ a ̃ o ~ C e n t r o ~ T e c n o l o ́ g i c o ~ d e ~ M i n a s ~ G e r a i s ~(C E T E C), ~ B e l o ~ H o r i z o n t e, ~ M G, ~ B r a s i l . ~}$ 
materiais para implante e técnicas para a fixação interna de fraturas em humanos.

As fraturas em ossos longos dos animais domésticos de grande porte são também frequentes, sendo um desafio maior para o médico veterinário, uma vez que a perda da função de um dos membros, quase sempre é incompatível com a vida. Além disso, associam-se problemas relacionados com o pósoperatório e a reabilitação, devido ao peso elevado desses animais, tornando inviável a permanência em estação por longos períodos, e a pressão sobre a sua musculatura causa lesões graves quando em decúbito por muito tempo (McCLURE et al., 1998). Nas últimas duas décadas, várias técnicas de fixação têm sido utilizadas no tratamento dessas fraturas. No entanto, um dos grandes problemas ainda existente é a não disponibilidade de dispositivos de fixação adequados e desenvolvidos especificamente para esses animais (AITHAL et al., 2004).

A haste intramedular bloqueada vem sendo utilizada com sucesso no tratamento de fratura de ossos longos em humanos (PIETRZAK et al., 1996; BHAT et al., 2006) e mais recentemente também em animais domésticos como cães (GIORDANO et al., 2006) e gatos (ROMANO et al., 2008). Tradicionalmente, essas hastes têm sido confeccionadas com aço inoxidável ou titânio, sendo muitos os registros de complicações relacionadas ao seu emprego, tais como: não união ou união retardada, quebra da haste ou dos parafusos, erros de bloqueio dos parafusos, infecções, neuropraxias, formações de pseudoartroses e contraturas musculares (GIORDANO et al., 2006). Some-se a isso o fato de que o uso de haste metálica rígida tem alto custo e pode promover reação do organismo ao material, interferência nas técnicas de acompanhamento pós-operatórias por imagem e restrição do crescimento ósseo fisiológico em pacientes jovens (PIETRZAK et al., 1996). Além disso, seu emprego promove, ao longo do tempo, diminuição da densidade mineral óssea (osteopenia), causada pela presença do material metálico (BÖSTMAN, 1991), consequência do efeito conhecido como blindagem de tensões (stress shielding). Assim, normalmente, uma segunda cirurgia deve ser realizada para remoção do implante após a consolidação da fratura (VAN DER ELST et al., 1999).

A busca por materiais mais leves, resistentes, de baixo custo e biocompatíveis tem crescido dia a dia (VAN DER ELST et al., 1999). Os polímeros têm sido progressivamente testados e incorporados em procedimentos cirúrgicos, com destaque para os implantes ortopédicos e os de reconstrução de tecidos. Em estudo prévio, nosso grupo determinou que fraturas de úmero em bovinos jovens podem ser tratadas com sucesso, usando o polipropileno em forma de haste intramedular bloqueada (DE MARVAL, 2006). Novos trabalhos vêm sendo realizados para se desenvolver um sistema de fixação por haste intramedular que possa ser aplicada ao fêmur desses animais (LOPES et al., 2007; RODRIGUES et al., 2009a; RODRIGUES et al., 2009b). No presente estudo, utilizaram-se testes biomecânicos ex vivo visando à avaliação da performance de sistemas de fixação por haste intramedular bloqueada com diferentes materiais poliméricos. Esses testes têm se tornado cada vez mais comuns na avaliação do desempenho dos dispositivos de fixação. Cargas fisiológicas são aplicadas aos ossos implantados para avaliar sua estabilidade e resposta mecânica (DALLABRIDA et al., 2005). Assim, o objetivo deste trabalho foi avaliar, ex vivo, a resistência mecânica a forças de compressão e flexão de fêmures de bovinos jovens com fratura diafiseal, imobilizados com hastes intramedulares bloqueadas, compostas por diferentes polímeros (polipropileno, poliacetal e poliamida), comparando-as com a resistência média verificada em fêmures íntegros. Também se objetivou confrontar os resultados dos testes ex vivo com resultados de estudos in vivo previamente publicados.

\section{MATERIAL E MÉTODOS}

Foram utilizados 24 fêmures de bezerros machos da raça Holandesa, com peso médio de $500 \mathrm{~g}$ (480g-520g), idade entre 15 e 30 dias, provenientes de abatedouros da microrregião de Belo Horizonte. Imediatamente após o abate, os ossos foram dissecados dos tecidos moles adjacentes, divididos aleatoriamente em quatro grupos iguais e acondicionados em sacos plásticos para serem conservados por congelamento a $-20^{\circ} \mathrm{C}$, conforme GALUPPO et al. (2002) e DALLABRIDA et al. (2005).

Em seguida, os ossos foram preparados para a realização dos testes físicos, sendo primeiramente descongelados à temperatura ambiente por 12 horas. Em um dos quatro grupos, os ossos foram mantidos íntegros (Grupo Controle). Nos outros três, os ossos foram fraturados e implantados com uma das hastes poliméricas selecionadas (polipropileno, poliacetal e poliamida), segundo metodologia proposta por DE MARVAL (2006). Os fêmures foram seccionados em sua diáfise, na transição entre os terços médio e proximal, de forma a simular uma fratura oblíqua. A incisão foi realizada em sentido crânio-distal para caudoproximal com serra em fita, em um ângulo de $40^{\circ} \mathrm{em}$ relação ao eixo longitudinal do osso, sendo o ponto 
inicial de corte localizado $20 \mathrm{~mm}$ distal ao trocanter maior. A redução da fratura foi feita pela aplicação retrógrada das hastes com $12 \mathrm{~mm}$ de diâmetro, após abertura do canal medular com uma broca de aço do mesmo diâmetro. Essa abertura foi realizada apenas na extensão do canal medular no fragmento distal e, no proximal, se estendeu até produzir abertura no trocanter maior dos fêmures. Para bloqueio das hastes, foram utilizados quatro parafusos de aço inoxidável $(4,5 \mathrm{~mm}$ de diâmetro e $50 \mathrm{~mm}$ de comprimento), sendo dois em cada fragmento, colocados de forma transversal ao eixo do osso, inseridos na face lateral de forma a perfurar a cortical de ambos os lados. Esse procedimento foi realizado após perfuração tanto da cortical, quanto da haste, com uma broca de aço de $3,2 \mathrm{~mm}$ de diâmetro. Depois de implantados, cada um dos grupos foi novamente dividido em dois subgrupos de seis ossos, para serem submetidos respectivamente a testes físicos de compressão e flexão.

Os testes físicos foram realizados no Laboratório Robert Hooke da Fundação Centro Tecnológico de Minas Gerais (CETEC). Foi utilizada uma Máquina Universal de Ensaios (Instron 5869, coluna dupla, capacidade de $50 \mathrm{kN}$, escala de velocidade de 0,001-500 $\mathrm{mm} \mathrm{min}^{-1}$ ).

Para os testes de flexão, os ossos foram apoiados sobre uma base de madeira maciça, de modo a garantir o alinhamento horizontal do eixo longitudinal do osso. A força foi aplicada no centro da diáfise, em seu terço médio, na face cranial, caracterizando um ensaio de flexão de três pontos (Figura 1C). Um pistão de aço foi fixado à extremidade móvel da máquina para aplicação da força no ponto indicado até que ocorresse a ruptura da haste, fissura do osso, angulação excessiva da haste em relação ao eixo longitudinal do osso ou ainda desalinhamento dos fragmentos ósseos.
Uma célula de carga (50kN, id. STF 100.02, Instron, modelo 2525-802 NS 44151) foi utilizada para o registro dos valores da força durante o ensaio.

No ensaio de compressão, a força foi aplicada ao longo do eixo longitudinal da amostra, no sentido proximal-distal. Para garantir o alinhamento do eixo longitudinal do osso na posição vertical, as extremidades ósseas foram seccionadas. Em seguida, para evitar o deslizamento do osso durante o teste de compressão, as extremidades foram colocadas em uma base composta de resina de polimetilmetacrilato, para permitir o apoio devido do osso no plano. Essas bases foram moldadas em cilindros de PVC, em que os ossos permaneceram imersos até a completa secagem da resina.

Os testes de compressão e de flexão se iniciavam com o contato do pistão sobre as amostras. O valor considerado para análise foi a força de ruptura, que correspondia à carga máxima registrada no momento imediatamente anterior à ruptura da amostra sob ação da força atuante. Essa ruptura era caracterizada por um aumento de deslocamento expressivo sem aumento do carregamento, correspondendo à perda de estabilidade da peça. Após esse momento, apesar de a amostra apresentar resistência menor, o teste teve continuidade até que houvesse completa falha estrutural, sendo assim possível verificar todos os pontos de fragilidade das amostras. Em ambos os testes, a velocidade de aplicação da carga foi de $0,5 \mathrm{~mm} \mathrm{~min}^{-1}$.

Após tabulação dos dados, compararam-se os resultados entre grupos, considerando separadamente os testes de compressão e flexão, por meio de análise de variância em desenho experimental inteiramente casualizado para dados com distribuição normal, e o teste de Kruskal-Wallis para dados sem

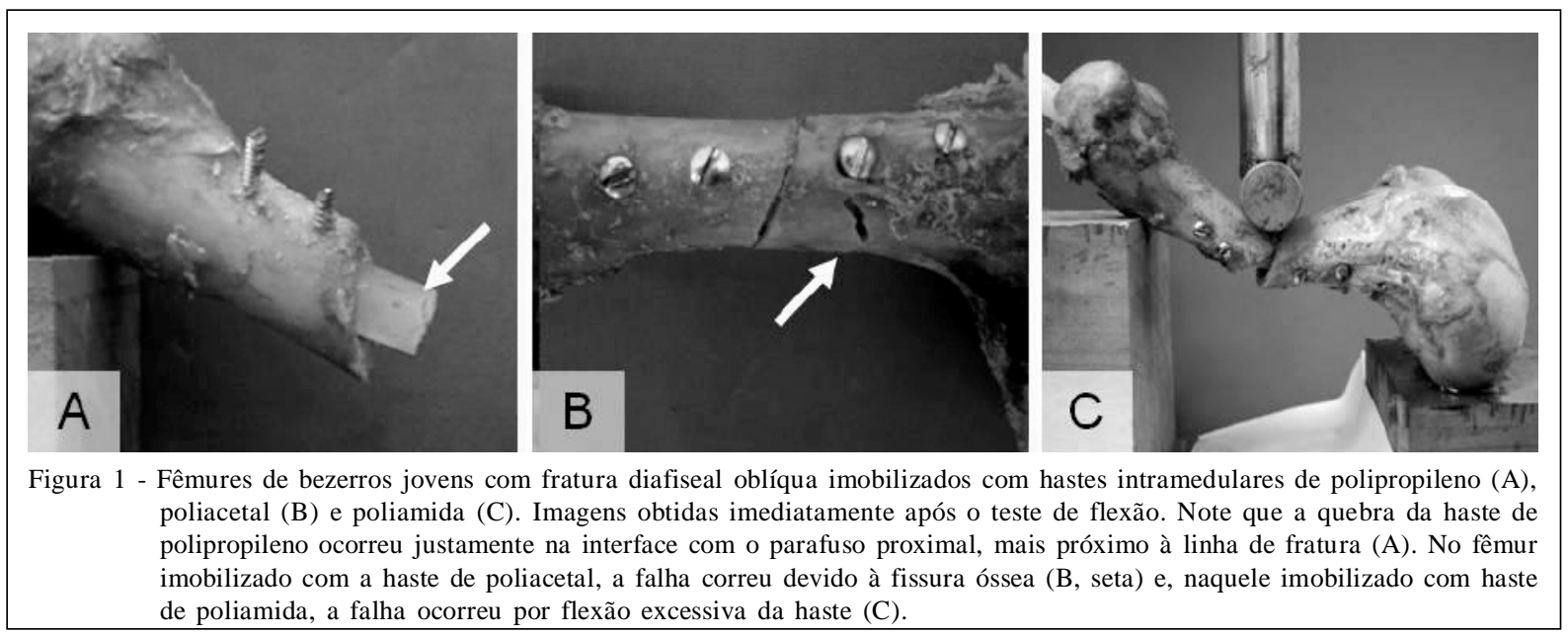

Ciência Rural, v.41, n.2, fev, 2011. 
distribuição normal. Para comparação das médias dos grupos, usou-se o teste de Student-Newman-Keuls. Todos os testes foram realizados com nível de significância equivalente a $\mathrm{P}<0,05$.

\section{RESULTADOS E DISCUSSÃO}

Nos testes de flexão em ossos íntegros, a fratura ocorreu sempre longitudinalmente ao longo da diáfise. Nos ossos submetidos à técnica de redução da fratura, o comportamento das amostras variou em função do tipo de haste utilizada. Nos ossos implantados com haste de polipropileno, as seis amostras utilizadas apresentaram fratura da haste. As hastes se romperam no exato local onde havia um parafuso transfixando-as e no ponto mais próximo do foco da fratura (Figura 1A). Resultado semelhante foi encontrado por DE MARVAL (2006), utilizando hastes de polipropileno em testes ex vivo com úmeros de bezerro. Estudos envolvendo simulação computacional de fêmures imobilizados por hastes intramedulares poliméricas demonstraram que as maiores tensões ocorrem sempre nos parafusos mais próximos ao local da fratura (RODRIGUES, 2008). DE MARVAL (2006) levantou a hipótese de que as maiores tensões ocorrerem nesses parafusos devido a uma maior mobilidade do conjunto na região próxima aos fragmentos ósseos.

Nos ossos implantados com hastes de poliacetal, em um caso, ocorreu a fratura da haste e, nos outros cinco, ocorreu a fissura do osso, o que comprometia a integridade do conjunto, caracterizando assim o fim do ensaio (Figura 1B). Nos seis ensaios com haste de poliamida, os conjuntos apresentaram angulação excessiva das extremidades ósseas, com o desalinhamento da haste em relação ao eixo longitudinal do osso (Figura 1C). Essa situação também foi considerada não aceitável para os ensaios, sendo eles interrompidos neste instante. No caso da haste de poliamida, não ocorreu a sua ruptura, tampouco a fissura do osso. Nos casos em que não ocorreu a fratura da haste e o ensaio foi interrompido, a força considerada correspondeu ao maior valor registrado antes da interrupção.

Nos testes de compressão com ossos íntegros, não houve fratura ao longo da diáfise, ocorrendo, primeiramente nos seis casos, o deslocamento da placa epifisária. Acredita-se que isso tenha ocorrido por ser essa região a de menor resistência dos ossos de animais jovens, devido a sua composição predominantemente orgânica, com um mínimo de base mineral (JEE, 2001). Essa situação foi considerada como uma fratura, pois comprometia a integridade do osso, tornando a continuidade dos ensaios inviável.

Nos ossos implantados com as hastes poliméricas, as falhas ocorreram principalmente por causa da perda de alinhamento entre os fragmentos ósseos. Fraturas nas hastes ocorreram em uma de polipropileno e em três de poliacetal, sendo que em uma destas também ocorreu o desprendimento do parafuso proximal mais próximo ao foco de fratura. Para os ossos implantados com hastes de poliamida, em um dos casos ocorreu fratura óssea. Resultado semelhante com o uso de hastes de polipropileno também foi encontrado por DE MARVAL (2006), utilizando hastes de polipropileno em testes de compressão ex vivo, com úmeros de bezerro.

Os resultados dos ensaios físicos estão representados na figura 2. Nos testes de flexão, apenas os ossos imobilizados com poliamida não apresentaram diferença significativa dos valores observados nos ossos íntegros. Contudo, em média, esses ossos

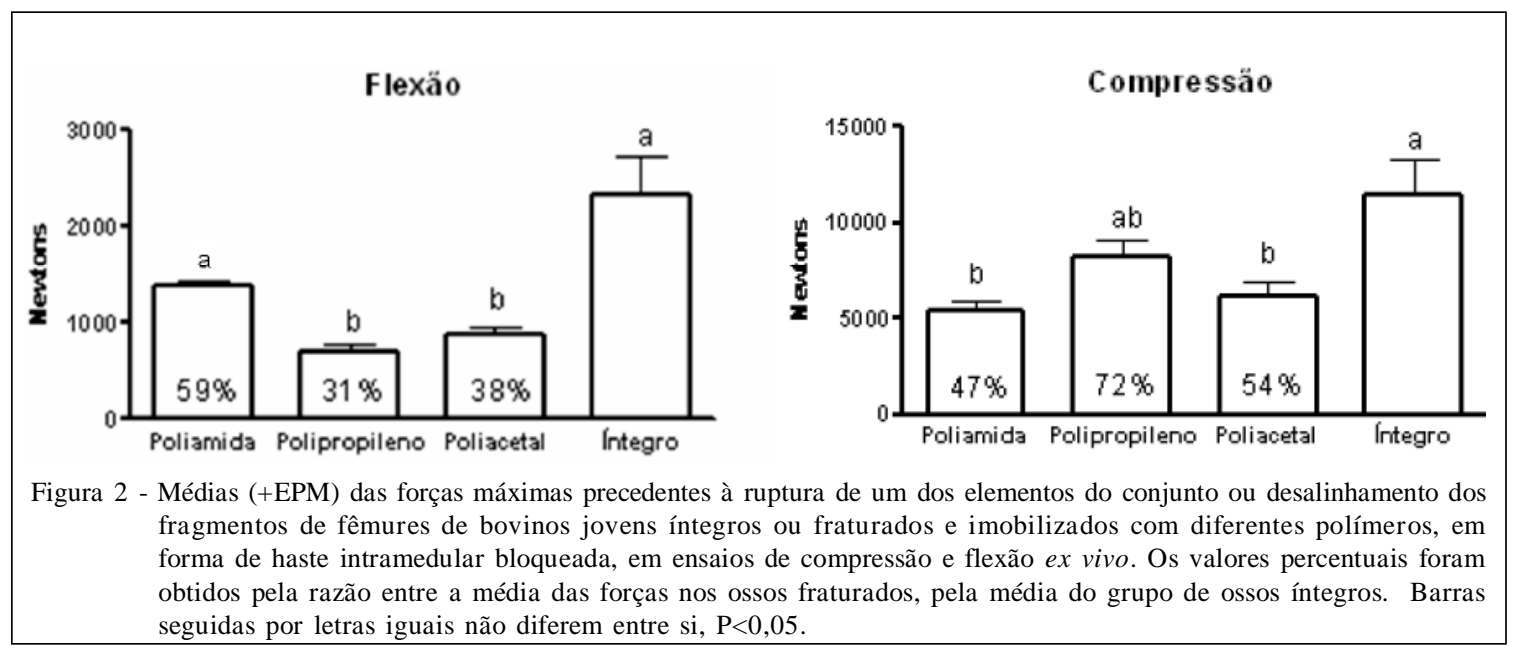

Ciência Rural, v.41, n.2, fev, 2011. 
suportaram apenas $58 \%$ das forças suportadas pelo osso íntegro. Nos testes de compressão, o grupo polipropileno apresentou melhor resultado, atingindo $72 \%$ dos ossos íntegros, sem haver diferença estatística, quando comparada com o grupo de ossos íntegros. Esta mesma haste de polipropileno mostrou resistência semelhante (66\%) à compressão, quando implantada em úmero (DE MARVAL, 2006).

Tanto ossos íntegros como fraturados apresentaram maiores valores de força máxima nos testes de compressão do que nos testes de flexão. Esse resultado era esperado pelo fato de que quando temos a carga aplicada no eixo axial, além da resistência da haste, que é muito maior no seu eixo longitudinal, temse ainda o apoio entre os fragmentos ósseos na linha de fratura. Nos testes de flexão, a partir do momento em que a força é aplicada na diáfise óssea, quase que toda a resistência é oferecida pela haste. Esses resultados corroboram achados de estudo ex vivo utilizando-se hastes de polipropileno em úmero bovino (DEMARVAL, 2006).

Com base nesta discussão e observandose os resultados que descrevem o comportamento das amostras, percebe-se que os ossos implantados com hastes de poliamida possuem superior resistência à flexão em relação às hastes de poliacetal e de polipropileno. Esse resultado está de acordo com a literatura técnica (VICK, 2008), que indica a poliamida com maior módulo de elasticidade à flexão (3200MPa) que os outros dois materiais (poliacetal: 2800MPa e polipropileno: 1600MPa). Esse parâmetro não pode ser desconsiderado uma vez que os esforços à flexão são predominantes na estrutura óssea, principalmente no período pós-operatório imediato, quando o sucesso da fixação depende exclusivamente do implante.

Considerando a resistência de cada polímero, o fato de a haste de polipropileno ter fornecido maior resistência no ensaio de compressão foi inesperado. Nesses ensaios, nos ossos instrumentados com haste de polipropileno, as extremidades ósseas eram facilmente aproximadas, aumentando assim a resistência do conjunto e trazendo uma possível explicação para os resultados observados. Flexibilidade semelhante também foi observada quando do uso de hastes de polipropileno nos bovinos (DE MARVAL, 2006).

Uma análise global dos resultados nos testes ex vivo, aliada às propriedades dos materiais estudados, indica que o polipropileno é o material com o desempenho menos satisfatório, pois apresentou pior resultado nos ensaios de flexão e, apesar do melhor resultado nos ensaios sob compressão, possui tensão de ruptura a compressão inferior em relação aos outros dois materiais. O poliacetal teve o segundo melhor desempenho nos dois ensaios e sua tensão de ruptura está entre os valores do polipropileno e da poliamida. Por apresentar melhor comportamento à flexão em relação ao polipropileno e ao poliacetal, a poliamida, que também possui maior módulo de resistência à flexão e maior tensão de ruptura à compressão, poderia ser considerada o material com maior chance de promover imobilização eficiente em um estudo in vivo. Analisando um estudo similar in vivo previamente publicado (SPADETO JUNIOR et al., 2010), observa-se concordância nos resultados, pois nesse estudo houve fratura em seis de sete hastes de poliacetal implantadas e em duas de quatro hastes de poliamida implantadas em fraturas diafiseais em bezerros, com 85 a 100 dias de idade. Coincidentemente, nesse mesmo estudo, todas as fraturas de hastes ocorreram na interface com os parafusos mais próximos à linha de fratura.

\section{CONCLUSÃO}

Independente do polímero utilizado (polipropileno, poliacetal ou poliamida), nenhuma das hastes estudadas ofereceu aos fêmures fraturados de bovinos jovens resistência comparável à do osso íntegro, quando consideradas em conjunto as forças de flexão e compressão. A concordância desses achados com resultados in vivo previamente publicados demonstra que a metodologia utilizada para testes ex vivo pode ser útil na seleção de materiais mais resistentes para confecção de novos modelos.

\section{AGRADECIMENTO E APRESENTAÇÃO}

\author{
À Coordenação de Aperfeiçoamento de Pessoal de \\ Nível Superior (CAPES), Fundação de Amparo à Pesquisa do \\ Estado de Minas Gerais (FAPEMIG), Fundação de Amparo à \\ Pesquisa do Estado da Bahia (FAPESB) e Pró-Reitoria de \\ Pesquisa da UFMG (PRPq-UFMG), pelo financiamento do \\ projeto. \\ O presente trabalho é parte da Tese de Doutorado \\ do segundo autor, Luciano Brito Rodrigues.
}

\section{COMITÊ DE ÉTICA}

Comitê de Ética em Experimentação Animal da UFMG (protocolos 145/04 e 136/09).

\section{REFERÊNCIAS}

AITHAL, H.P. et. al. The use of a circular external skeletal fixation device for the management of long bone osteotomies in large ruminants: an experimental study. Journal of Veterinary Medicine Series A- Physiology Pathology Clinical Medic, v.51, p.284-293, 2004. Disponível em: <http://www3.interscience.wiley.com/journal/118788784/ abstract?CRETRY=1\&SRETRY=0>. Acesso em: 01 jun. 2009. doi: $10.1111 / \mathrm{j} .1439-0442.2004 .00638 . x$. 
BHAT, A.K. et al. Mechanical failure in intramedullary interlocking nails. Journal of Orthopaedic Surgery, v.14, n.2, p.138-141, 2006. Disponível em: <http://www.josonline.org/ pdf/v14i2p138.pdf>. Acesso em: 01 jun. 2009.

BÖSTMAN, O. Absorbable implants for the fixation of fractures. Journal of Bone and Joint Surgery, v.73, n.1, p.148-153, 2001. Disponível em: <http://www.ejbjs.org/cgi/ reprint/73/1/148.pdf. Acesso em: 01 jun. 2009.

DALLABRIDA, A.L. et al. Análise biomecânica ex vivo de dois métodos de osteossíntese de fratura diafisária transversal em fêmur de cães. Ciência Rural, v.35, n.1, p.116-120, 2005. Disponível em: $<$ http://www.scielo.br/scielo.php?script=sci_arttext\&pid=S0103$84782005000100018 \& \operatorname{lng}=$ pt\&nrm=iso>. Acesso em: 01 jun. 2009. doi: $10.1590 / \mathrm{S} 0103-84782005000100018$.

DE MARVAL, C.A. Estudo ex vivo e in vivo de polímero biocompatível como material alternativo na confecção de haste bloqueada para redução de fraturas em úmeros de bezerros. 2006. 54f. Dissertação (Mestrado em Medicina Veterinária) - Programa de Pós-graduação em Medicina Veterinária, Escola de Veterinária, Universidade Federal de Minas Gerais, MG.

GALUPPO, L.D. et al. An in vitro biomechanical investigation of an MP35N intramedullary interlocking nail system for repair of third metacarpal fractures in adult horses. Veterinary Surgery, v.31, n.3, p. 211-225, 2002. Disponível em: <http:/ /pi2.ingenta.com/content/bsc/vsu/2002/00000031/00000003/ art00004; jsessionid=b01obt101 kdij.alice>. Acesso em: 01 jun. 2009. doi: $10.1053 /$ jvet.2002.32400.

GIORDANO, P.P. et al. Haste intramedular bloqueada modificada aplicada ao fêmur. Estudo clínico e experimental em cães. Ars Veterinaria, v.22, p.184-191, 2006. Disponível em: <http://www.arsveterinaria.org.br/index.php/ars/article/ viewFile/102/90>. Acesso em: 01 jun. 2009.

JEE, W.S.S. Integrated bone tissue physiology: anatomy and physiology. In: COWIN, S.C. (Ed.). Bone mechanics handbook. Boca Raton, FL: CRC, 2001. Cap1, 1.1-1.68.

LOPES, D.S. et al. A geometric modelling pipeline for bone structures based on computed tomography data: a veterinary study. In: TAVARES, J.M.R.S.; NATAL JORGE, R.M. Computational vision and medical image processing. Oxford: Tay.lor \& Francis, 2007. p.217-222.

McCLURE, S.R. et al. In vitro evaluation of intramedullary interlocking nail fixation of transverse femoral osteotomies in foals. Veterinary Surgery, v.27, p.29-36, 1998.

PIETRZAK, W.S. et al. Bioresorbable implants - practical considerations. Bone, v.19, suppl.1, p.109S-119S, 1996. Disponível em: http://www.journals.elsevierhealth.com/
periodicals/bon/article/S8756-3282\%2896\%2900139-1/pdf. Acesso em: 01 jun. 2009.

RODRIGUES, L.B. Análise computacional e ex vivo de uma técnica de redução de fraturas para ossos longo de grandes animais. 2008. 206f. Tese (Doutorado em Engenharia Mecânica). Programa de Pós-graduação em Engenharia Mecânica, Escola de Engenharia. Universidade Federal de Minas Gerais, MG

RODRIGUES, L.B. et al. Medição das forças de reação do solo em bovinos jovens nas situações de caminhada e de parada utilizando a plataforma de força. Revista Brasileira de Biomecânica, v.10, p.54-60, 2009a. Disponível em:< http:/ /citrus.uspnet.usp.br/biomecan/ojs/index.php/rbb/article/view/ 94>. Acesso em: 01 maio, 2010.

RODRIGUES, L.B. et al. Bone remodeling analysis of a bovine femur for a veterinary implant design. Computer Methods in Biomechanics and Biomedical Engineering. v.12, n.6, p.683690, 2009b. Disponível em: <http://www.informaworld.com/smpp/ content $\sim$ content $=\mathrm{a} 910351161 \& \mathrm{db}=\mathrm{all}>$. Acesso em: 01 jun. 2009. doi: $10.1080 / 10255840902865641$

ROMANO, L. et al. Avaliação do uso de haste bloqueada e bloqueio transcortical no reparo de fraturas diafisárias de fêmur em felinos. Pesquisa Veterinária Brasileira, v.28, n.4, p.201-206, 2008. Disponível em: <http://www.scielo.br/pdf/ pvb/v28n4/v28n4a02.pdf>. Acesso em: 01 jun. 2009. doi: 10.1590/S0100-736X2008000400002.

SPADETO JUNIOR, O. et al. Falhas na utilização de poliacetal e poliamida em forma de haste intramedular bloqueada para imobilização de fratura femural induzida em bovinos jovens. Ciência Rural, v.40, n.4, p.907-912, 2010. Disponível em $<$ http://www.scielo.br/scielo.php?script=sci_arttext\&pid=S0103$84782010005000038 \& \operatorname{lng}=\mathrm{pt} \& \mathrm{nrm}=\mathrm{iso}>$. Acesso em 02 abr. 2010. doi: $10.1590 / \mathrm{S} 0103-84782010005000038$.

VAN DER ELST, M. et al. Bone tissue response to biodegradable polymers used for intra medullary fracture fixation: a long-term in vivo study in sheep femora. Biomaterials, v.20, p.121-128, 1999. Disponível em: <http://www.sciencedirect.com/ science?_ob=ArticleURL\&_udi=B6TWB-3 X7 VRK 8 $3 \&$ u ser $=10 \&$ \& cover Date $=01 \% 2$ F $31 \% 2$ F 199 $9 \&$ \& r oc $=1 \&$ \&_fmt $=$ high \&_orig =search\&_sort $=$ d\&_docanchor $=\&$ view $=c \& \_a c c t=C 000050221 \& \_$version $=1 \&$ _ u r $1 \mathrm{~V}$ e r s i o $\mathrm{n}=0 \&$ u s e r i d $=10 \& \mathrm{~m} \mathrm{~d} 5$ $=7 \mathrm{fdab} 2 \mathrm{c} 7 \mathrm{c} 78 \mathrm{~d} 3 \mathrm{ecd} 736 \mathrm{ef} 7319 \mathrm{fa} 78 \mathrm{f} 1 \mathrm{~b}>$. Acesso em: $02 \mathrm{de}$ abr. 2010. doi: 10.1016/S0142-9612(98)00117-3.

VICK, 2008. Vick comércio de plásticos e isolantes. Tabelas Técnicas. Disponível em: <http://www.vick.com.br/vick/ index2.htm.>. Acesso em: 02 abr. 2010. 